\title{
Radioecological risk assessment in tropical climate countries
}

\author{
E.R.R. Rochedo ${ }^{1}$, M.A.V. Wasserman ${ }^{2}$ and G.C. Barata ${ }^{2}$ \\ ${ }^{1}$ Coordenação de Instalações Nucleares/CNEN, R. Passagem 123, $9^{\circ}$ andar, 22290-030 \\ Rio de Janeiro, RJ, Brasil \\ e-mail: erochedo@cnen.gov.br; \\ ${ }^{2}$ Instituto de Radioproteção e Dosimetria/CNEN, Av. Salvador Allende s/ No., 22780-160 \\ Rio de Janeiro, RJ, Brasil
}

\begin{abstract}
Since the 90's the relevance of considering environmental aspects in development industrial activities has been steadily growing. The anthropocentric philosophy of radiological protection has been questioned and research and development on ecological risk assessment has now an import role in overall risk assessment procedures. However, most development up to now has focused temperate climate country biota and cannot be directly applied to tropical climate countries, due to the very different environmental characteristics and biodiversity. A preliminary survey focusing the area surrounding the Brazilian nuclear power plant site has shown that very few of the ICRP's reference animals and plants can be used to characterize environmental protection in tropical climate areas. The development of such lists and all the research needed on parameter values to fulfill a risk assessment procedure would be extremely expensive, and more pragmatic approaches are needed to turn the process reliable in a more global way.
\end{abstract}

\section{INTRODUCTION}

Since the 90's the relevance of considering environmental aspects in development industrial activities has been steadily growing. The anthropocentric philosophy of radiological protection has been questioned and research and development on ecological risk assessment has now an import role in overall risk assessment procedures. However, most development up to now has focused temperate climate country biota and cannot be directly applied to tropical climate countries, due to the very different environmental characteristics and biodiversity.

ICRP publication 108 [ICRP, 2008] defines a list of very specific animals and plants to be used for environment protection assessments. However, this list clearly focuses species from temperate climate countries. Of course it reflects the large set of environmental studies performed in Northern hemisphere countries, as main users of nuclear energy but also due to the consequences of Chernobyl accident.

However, this document fails in classifying this list as generically and in suggesting that it may be applicable to the whole world. This study aimed to verify the applicability of ICRP's list of reference animals and plants to perform environmental assessments in Brazil, with a focus on the surroundings of main nuclear re installations and fuel cycle facilities in Brazil.

\section{METHODOLOGY}

A preliminary survey focusing the area surrounding the Brazilian nuclear power plant site has shown that very few of the ICRP's reference animals and plants [1] were found in that area.

The Brazilian Nuclear Power Plant is located in the seashore, surrounded by mountains up to 700 $\mathrm{m}$ high covered by typical Atlantic tropical forests [2]. Main source of information for this area was the Environmental Impact Report for Angra III Power Plant [2]. The environment surrounding the Nuclear Fuel Facility is also characterized as tropical Atlantic Forest. It is located is at $750 \mathrm{~m}$ above sea level, and surrounded by mountains up to $2900 \mathrm{~m}$ high. The Caetité uranium mining is located in a semi-arid 


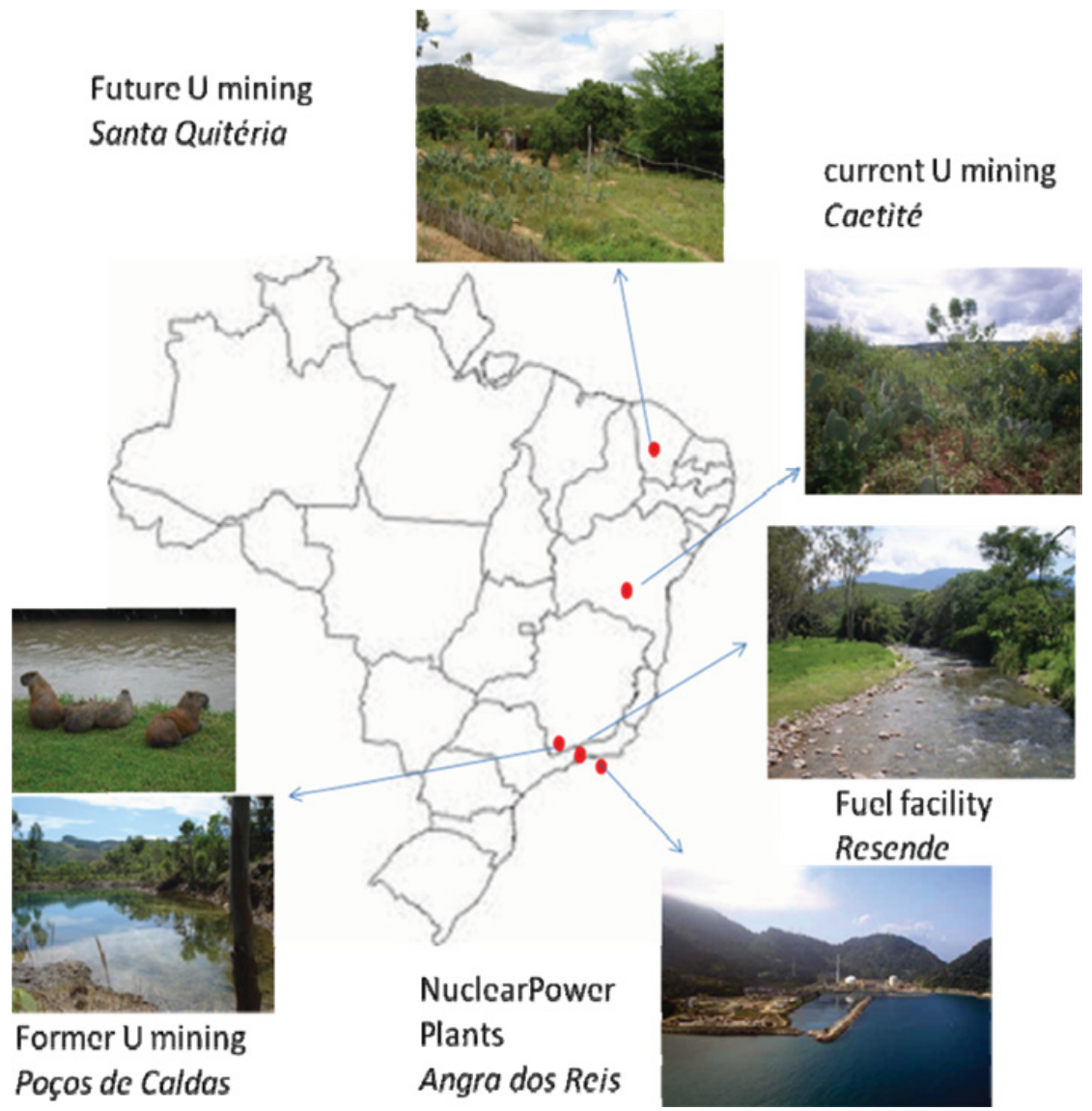

Figure 1. Typical environments of nuclear and fuel cycle facilities in Brazil.

region; the former uranium mining, in Poços de Caldas, is surrounded by agricultural areas in a region with a rainfall rate around $1700 \mathrm{~mm} / \mathrm{a}$; a new uranium mining is being licensed at the north-east arid region (Santa Quitéria).

The main site used as a reference site in Brazil was the area surrounding the Brazilian Nuclear Power plants, in the Southwest of Brazilian Coast. Comments are also included to address the nuclear fuel fabrication facility and three uranium mining areas. Typical environments in the areas assessed are shown in Figure 1.

\section{RESULTS AND DISCUSSION}

The comparison of ICRP reference biota list with biota typical for the southeast Brazilian coast is presented on Table 1. It can be observed that from the 12 categories defined by ICRP, 7 are not adequate to represent local fauna and flora. The large terrestrial mammals, the large terrestrial tree, and the freshwater fish reference animals from ICRP are inexistent at the area, despite the large biodiversity found in the area, as usual in tropical forest areas. Duckling ducks, hibernating frogs, large crabs and bees, although may be eventually found in the area, are not typical or permanent, making them not adequate to guarantee an adequate protection for the tropical biota.

Besides that, the absence of reptiles on ICRP list exemplifies its inadequacy to tropical natural environments. The large biodiversity of snakes, turtles and lizards and its relevance to tropical 
Table 1. Comparison of ICRP reference biota with Biota on the surroundings of Brazilian Nuclear Power Plants.

\begin{tabular}{|c|c|c|}
\hline Type & Reference biota [1] & Study area [2] \\
\hline large terrestrial mammal & Deer & non existent \\
\hline small terrestrial mammal & Rat & Existent \\
\hline aquatic bird & Duck & not typical, only wild migrating ducks \\
\hline Amphibian & Frog & several species but none \\
\hline & & with winter hibernating habits \\
\hline freshwater fish & Trout & non existent \\
\hline marine fish & Flatfish & existent \\
\hline terrestrial insect & Bee & existent but several other species \\
\hline marine crustacean & $\mathrm{Crab}$ & $\begin{array}{l}\text { smaller crabs with different } \\
\text { would be more representative } \\
\text { characteristics }\end{array}$ \\
\hline terrestrial annelid & Earthworm & existent \\
\hline large terrestrial plant & Pine Tree & non-exisntent \\
\hline small terrestrial plant & Wild Grass & Existent \\
\hline seaweed & Brown Seaweed & Existent \\
\hline
\end{tabular}
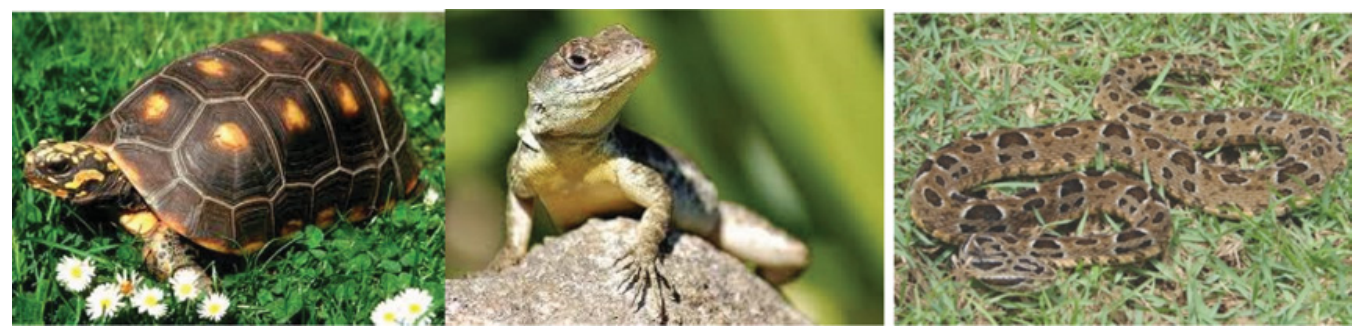

Figure 2. Relevant tropical biota forgotten by ICRP at their representative list [1].

ecosystems demands the inclusion of these reference animals in any impact assessment in tropical and equatorial areas (Figure 2). These species are present in substantial amount in all sites studied in Brazil. Chelonioidea, in particular, are preserved species in all the country, for both terrestrial and aquatic environments. Alligators are present in most terrestrial aquatic environments all through the country. Lizards and snakes are part of human food chain in some parts of the country.

UNSCEAR has recently published an update on scientific knowledge on the effects of atomic radiation in non-human biota [3]. This review confirms previous results on different species sensitivity to radioactivity in the environment [4]. Mammals are still considered as the most sensitive group, followed by birds and them by higher plants. The range of lethal doses for higher plants, however, span for about three orders of magnitude. Considering UNSCEAR review, only a few exposure situations can be foreseen related to doses to non-human biota in levels of concern for their protection.

Within the concept of critical group/representative person [5, 6], routine releases acceptable for human beings shall hardly pose any danger to other species. One possible exception is the radioactive waste disposal. As human beings shall be more protected than some specific biota species, this should be subject of specific environmental protection regulation or agreement under the Joint Convention Safety of Spent Fuel Management and on the Safety of Radioactive Waste Management [7].

Other exposure situations that can be foreseen have already been treated by conventions, such as the Comprehensive Nuclear Test Ban Treaty, and the Convention on the Prevention of Marine Pollution by Dumping of Wastes and Other Matter [8,9]. We can also mention accidents, as the protective measures to protect humans, such as evacuation, sheltering and relocation, are not applicable to biota in a general 
way. The most relevant actions however are the improvement of safety and accident prevention and preparedness.

Clearly, the need of specifically including non-human biota on impact assessments is not necessary on situations in which the critical human group is representative of highest exposures. When this is not the case, specific regulation will be needed and methodologies, such as that presented by ICRP will be needed. But it makes no sense to verify compliance for tigers and lions with any standard by assessing doses to a representative deer.

In order to suit best the different environments worldwide, generic animals should be described based on their main characteristics, rather than specific species. For example, different animal species should be described based on characteristics such as type (mammal, fish, reptile, etc.), size (small, medium, large) and diet (carnivorous, vegetarian); the description of vegetables should be based on characteristics such as size, leaves turn over period, lifetime and the ability of fruit production. The generic species could them be more acceptable to be adapted to different climate and ecosystems.

\section{CONCLUSIONS}

The ICRP reference list, although interesting as a preliminary overview of addressing the protection of the environment regarding non-human biota, is too specific to be adopted worldwide. It could be used as an example for temperate climate environments. But the development of such lists in local or even in a regional basis, considering all the research needed on parameter values to fulfill a risk assessment procedure, would be extremely expensive. More pragmatic approaches are needed to turn the process reliable in a more global way. The ICRP list should be improved to address species in a more generic way, in order to be useful for other areas in the planet.

\section{References}

[1] ICRP. Environmental Protection: the Concept and Use of Reference Animals and Plants. Publication 108. Ann. ICRP 38 (4-6) 1-242 (2008)

[2] Eletronuclear. Environmental Impact Report- RIMA da Unidade 3 da Central Nuclear Almirante Álvaro Alberto. In http://www.eletronuclear.gov.br/pdf/relatorio_de_impacto_ambiental.pdf (1996)

[3] UNSCEAR. Effects of ionizing radiation on non-human biota. 2008 Report: Sources and effects of ionizing radiation, V.2, Annex E (2011)

[4] UNSCEAR. Effects of radiation on the environment. 2006 Report: Sources and Effects of ionizing Radiation (2006)

[5] IAEA. International Basic Safety Standards for Protection against Ionizing Radiation and for the Safety of Radiation Sources, Safety Series No. 115, IAEA, Vienna (1996)

[6] ICRP. Assessing Dose of the Representative Person for the Purpose of the Radiation Protection of the Public. ICRP Publication 101a. Ann. ICRP 36 (3), 2006

[7] International Atomic Energy Agency. Joint Convention Safety of Spent Fuel Management and on the Safety of Radioactive Waste Management. In: www-ns.iaea.org/conventions/wastejointconvention.htm (2011)

[8] London Convention and Protocol (1972). In: http://www.imo.org/OurWork/Environment/ SpecialProgrammesAndInitiatives/Pages/London-Convention-and-Protocol.aspx

[9] Comprehensive Nuclear Test Ban Treaty (1996). In: http://www.ctbto.org/the-treaty/ 